\title{
Effect of Salt Forms of Chitosan on In Vitro Permeability Enhancement in Intestinal Epithelial Cells (Caco-2)
}

\author{
Thisirak Woraphatphadung, Jariya Kowapradit, Tanasait Ngawhirunpat, \\ Theerasak Rojanarata and Praneet Opanasopit \\ Pharmaceutical Development of Green Innovations Group (PDGIG), Faculty of Pharmacy, Silpakorn University, Nakhon \\ Pathom 73000, Thailand
}

*For correspondence: Email: praneet@su.ac.th; Tel: +66-34-255800; Fax: +66-34-250941

\begin{abstract}
Purpose: To investigate the effect of chitosan (CS) salt forms and $\mathrm{pH}$ condition on the transepithelial electrical resistance (TEER) of Caco-2 cell monolayer for enhanced permeability.

Methods: Solutions (2 \%w/v) of four different salt forms of CS-aspartate (CS-A), CS-ethylene diamine tetraacetate (CS-EDTA), CS-hydroxybenzotriazole (CS-HOBt) and CS-thiamine pyrophosphate (CSTPP) - were prepared and tested on TEER using fluorescein isothiocyanate dextran 4,400 (FD-4) as the permeant across Caco-2 cell monolayer in both pH 6.2 and 7.4 (physiological pH) environment.

Results: The results show that CS-salt solutions, at $\mathrm{pH}$ of 6.2 , increased cell permeability in a dosedependent manner and caused relatively reversible effects only at low doses of $0.001-0.010 \% \mathrm{w} / \mathrm{v}$. At CS-salt solution concentration of $0.01 \% \mathrm{w} / \mathrm{V}$, accumulation of FD-4 in the acceptor compartment was in the rank order: CS-EDTA > CS-TPP > CS-A > CS-HOBt. All CS-salt solutions significantly $(p<0.05)$ increased the transport of FD-4. On the other hand, at pH 7.4, only CS-EDTA at a concentration of 0.5 $\%$ w/v enhanced the transport of FD-4. CS-EDTA was also the most toxic CS salt.

Conclusion: The salt forms of CS are capable of enhancing the transport of FD-4 across Caco-2 cell monolayer, with CS-EDTA the most promising of them.
\end{abstract}

Keywords: Chitosan salts, Fluorescein isothiocyanate dextran, Transport, Absorption enhancer, Caco2 cells

Tropical Journal of Pharmaceutical Research is indexed by Science Citation Index (SciSearch), Scopus, International Pharmaceutical Abstract, Chemical Abstracts, Embase, Index Copernicus, EBSCO, African Index Medicus, JournalSeek, Journal Citation Reports/Science Edition, Directory of Open Access Journals (DOAJ), African Journal Online, Bioline International, Open-J-Gate and Pharmacy Abstracts

\section{INTRODUCTION}

Chitosan (CS) is used as a novel carrier of drugs for oral and intravenous administration. It has been documented that chitosan enhances drug absorption across intestine into blood in animals [1]. CS is a polycationic polymer at acidic $\mathrm{pH}$ with numerous applications in the food, agricultural, cosmetic and pharmaceutical industries. Advantages of this polymer include high availability, low cost, high biocompatibility, biodegradability, and ease of chemical modification.
In many studies, it has been demonstrated that CS-based formulations are superior in enhancing absorption of therapeutic proteins. CS is soluble, mucoadhesive and effective as an absorption enhancer only in its protonated form [2]. Functional groups (amine and hydroxyl) are present in CS, and various chemical chitosan derivatives have been synthesized and studied for different applications. However, chemical modification of chitosan normally utilizes strong organic solvent that might be residual in the product and/or in the medium. Among water soluble CS, CS-salts are easier to prepare and have no need for organic solvent, acid or heat. 
CS-salts are soluble in water and exhibit favorable biological properties such as nontoxicity, biocompatibility and biodegradability. They have attracted much interest in pharmaceutical research as polymeric drug carriers and as a novel drug absorption enhancer across nasal and intestinal epithelium [3,4].

Although, CS-salts have been reported to be used for biomedical applications such as drug and protein delivery, and transfection of DNA/siRNA [5,6], some CS-salts such as ethylenediaminetetraacetic acid (EDTA), hydroxybenzotriazole (HOBt), and thiamine pyrophosphate (TPP) have not yet been investigated for absorption enhancement. EDTA is well known as a metal chelator and widely used in textile, food, and pharmaceutical industries, while, $\mathrm{HOBt}$ (a derivative of benzotriazole) is used to improve efficiency of peptide synthesis. TPP is a thiamine derivative. It is a coenzyme present in all living systems where it catalyzes several biochemical reactions [7].

Therefore, the objective of the present study was to evaluate CS-salts solution of EDTA, HOBt, and TPP for their in vitro absorption enhancement on transepithelial electrical resistance (TEER) and permeability of Caco-2 cells monolayers by using FITC-dextran (FD-4) as a model hydrophilic drug macromolecule; a secondary objective was to compare their cytotoxicity with that of CS aspartate which has been reported as an absorption enhancer[8].

\section{EXPERIMENTAL}

\section{Materials}

Chitosan (degree of deacetylation 0.85, MW 110 $\mathrm{kDa}$, aspartic acid, ethylene diamine tetraacetate (EDTA), thiamine pyrophosphate (TPP), hydroxybenzotriazole monohydrate (HOBt·H2O), 3-(4,5-dimethylthiazol-2-yl)-2,5diphenyl tetrazolium bromide (MTT), fluorescein isothiocyanate dextran 4,400 (FD-4) were purchased from Sigma-Aldrich Chemical Co. (MO, USA). Dulbecco's modified Eagle's medium (DMEM), trypsin-EDTA, fetal bovine serum (FBS), glutamine, sodium pyruvate and penicillinstreptomycin antibiotic were obtained from Gibco-Invitrogen (NY, USA). Caco-2 cell line was obtained from American Type Culture Collection (Rockville, MD, USA).

\section{Preparation of chitosan salts}

Chitosan (CS) salts prepared from four acids: aspartic acid, ethylene diamine tetraacetate, thiamine pyrophosphate and hydroxybenzo- triazole. The method used was as described in a previous report [9]. Briefly, $2 \% \mathrm{w} / \mathrm{v}$ of CS-salt solution was prepared by simply mixing the chitosan and the acids in water overnight at a ratio of 1:1 for chitosan thiamine pyrophosphate (CS-TPP) and chitosan hydroxybenzotriazole (CS-HOBt), 2:1 for chitosan ethylene diamine tetraacetate (CS-EDTA) and 1.5:1 for chitosan aspartate (CS-A). After mixing, the $\mathrm{pH}$ of the CSsalt solution was adjusted to 6.2 or 7.4 with $1 \mathrm{~N}$ $\mathrm{HCl}$ or $1 \mathrm{~N} \mathrm{NaOH}$, and centrifuged to separate precipitants. The precipitants were lyophilized in a freeze-dryer (Labconco, Freezone 2.5, USA) for 3 days.

\section{Cell culture}

Caco-2 cells were maintained in Dulbecco's modified Eagle's medium (DMEM) at $\mathrm{pH} 7.4$, supplemented with $10 \%$ fetal bovine serum, 2 $\mathrm{mM}$ L-glutamine, $1 \mathrm{mM}$ sodium pyruvate, $1 \%$ non-essential amino acid solution, $0.1 \%$ penicillin-streptomycin in a humidified atmosphere $\left(5 \% \mathrm{CO}_{2}, 95 \%\right.$ air, $\left.37^{\circ} \mathrm{C}\right)$. The cells were grown under standard conditions until $60-70 \%$ confluency. Routine passing of cell stocks was carried out in $75-\mathrm{cm}^{2}$ flasks. Cells from passages 35 - 45 were used for all experiments.

\section{Measurement of trans-epithelial electrical resistance (TEER)}

The cells were seeded on tissue culture polycarbonate membrane filters (pore size, 3.0 $\mu \mathrm{m}$ ) in 12-well Transwell $^{\circledR}$ plates (Corning Life Sciences (Massachusetts, USA). at a seeding density of $6 \times 10^{4}$ cells $/ \mathrm{cm}^{2}$. The culture medium was added to both the donor and the acceptor compartments and the medium changed every second day. The cells were left to differentiate for 3 weeks after seeding with monitoring of transepithelial electrical resistance (TEER) values of $>$ $600 \Omega . \mathrm{cm}^{2}$ using a Millicell ${ }^{\circledR}$ ERS meter (Millipore, Bedford, MA, USA). Solutions of each of the four CS-salts $(0.001-1 \% \mathrm{w} / \mathrm{v})$ were prepared in Hank's balanced salt solution (HBSS) buffered at the same $\mathrm{pH}$ as the CS-salt solutions (6.2 and 7.4). One hour before the start of each experiment, the cells were washed twice with phosphate buffered saline (PBS) and preequilibrated with HBSS buffered at $\mathrm{pH}$ 7.4. After removing the medium, the Caco-2 cell monolayers were treated with CS-salt solution $(0.001-1 \% \mathrm{w} / \mathrm{v})$ at apical compartment. TEER was measured every $20 \mathrm{~min}$. After $2 \mathrm{~h}$ treatment, the cells were carefully washed twice with PBS and incubated with a fresh culture medium. Recovery of TEER values was monitored for 48 $\mathrm{h}$ after treatment. Control experiments, without 
CS-salt solutions, were done under the same conditions. Experiments were carried out in triplicate at $37{ }^{\circ} \mathrm{C}$ in an atmosphere of $95 \%$ air and $5 \% \mathrm{CO}_{2}$. Resistance was expressed as $\%$ TEER of initial value.

\section{Transport studies}

The transport of FD-4 across the Caco- 2 cell monolayer was carried out on Caco-2 monolayers grown in Transwell ${ }^{\circledR}$ (12-well) plates when they had differentiated and the monolayer was intact, as checked by measuring TEER. Prior to the experiment, the cells were washed twice with PBS and pre-equilibrated for $1 \mathrm{~h}$ with HBSS buffered at $\mathrm{pH}$ 7.4. After removing the medium, the cells were treated with CS-salt solutions at the recovered cell concentration $(0.01 \% \mathrm{w} / \mathrm{v}$ for $\mathrm{pH} 6.2$ and $0.5-1 \% \mathrm{w} / \mathrm{v}$ for $\mathrm{pH}$ 7.4) at apical compartment for $2 \mathrm{~h}$. In the control wells, the same media but without CS-salt solutions were used. In all cases, the basolateral medium used was Hanks' balanced salt solution (HBSS, pH 7.4). After $2 \mathrm{~h}$ treatment, the cells were carefully washed twice with PBS and FD-4 solution $(1 \mathrm{mg} / \mathrm{ml})$ was added on the apical side of the monolayers. Since FD-4 is a negatively charged polymer, the aggregation would form strong electrostatic interactions with the positively charged CS. Therefore, FD-4 was added after CS-salts solution incubation. Samples $(1000 \mu \mathrm{l})$ were taken under sink conditions at 30,60, 90, 120, 180 and $240 \mathrm{~min}$ from the basolateral side and replaced with an equal volume of fresh HBSS solution. The amount of FD-4 was determined using a fluorescence 96-wells plate reader (Universal Microplate Analyzer, Model AOPUS01 and Al53601, Packard BioScience, CT, USA). The excitation and emission wavelengths were 400 and $535 \mathrm{~nm}$, respectively. The results were expressed as \% cumulative transport as a function of time. All experiments were done in triplicate at $37{ }^{\circ} \mathrm{C}$. Apparent permeability coefficient was calculated according to Eq 1.

$P_{a p p}=(d Q / d t) \times\left(1 / A C_{o}\right)$

where $P_{\text {app }}$ is the apparent permeability coefficient $(\mathrm{cm} / \mathrm{s}), d Q / \mathrm{d} t(\mu \mathrm{g} / \mathrm{s})$ the rate of appearance of FD-4 on the basolateral side, $A$ is the surface area of the monolayers, and $C_{0}$ $(\mu \mathrm{g} / \mathrm{ml})$ is the initial FD-4 concentration in the donor compartment. All rate constants were obtained from the permeation profiles of each compound. Absorption enhancement ratio (R) was calculated from $P_{\text {app }}$ values as in Eq 2 [10].

$R=P_{\text {app }}($ sample $) / P_{\text {app }}$ (control)

\section{Cytotoxicity study}

The acute cytotoxic effect of CS-salt solutions at $\mathrm{pH} 6.2$ and 7.4 on cell viability was measured using MTT assay. MTT is a tetrazolium salt which is cleaved to a dark blue product by mitochondrial dehydrogenases in living but not in dead cells [11]. Caco-2 cells used for MTT assay were seeded at a density $2 \times 10^{4}$ cells/well in 96well cell culture plates and pre-incubated for $24 \mathrm{~h}$ before treatment. The cells were then treated with CS-salt solutions at various concentrations $0.001-1 \% \mathrm{w} / \mathrm{v}$ in serum-free medium $\mathrm{pH} 6.2$ and 7.4 for $24 \mathrm{~h}$. Dilute CS-salt solutions was made by using serum-free medium to ensure that the cells did not die from nutrition deficiency. After treatment, CS-salt solution was removed and fresh cell culture medium was added and incubated for $4 \mathrm{~h}$ to stabilize the cells. Finally, the cells were incubated with $100 \mu \mathrm{l}$ MTT containing medium $(0.1 \mathrm{mg} / \mathrm{ml}$ MTT in serum-free medium) for $4 \mathrm{~h}$. The medium was removed, and the formazan crystal formed in living cells was dissolved in $100 \mu \mathrm{l}$ DMSO per well. Relative cell viability (V, \%) was calculated based on absorbance at $550 \mathrm{~nm}$ (Eq 3) using a microplate reader (Universal Microplate Analyzer, model AOPUS01 and Al53601, Packard BioScience, CT, USA). Viability of non-treated control cells was arbitrarily defined as $100 \%$.

$V(\%)=\{(A s-A b) / A c-A b)\} 100$

where $A s, A b$ and $A c$ are the absorbance of the test sample, blank and control, respectively.

\section{Statistical analysis}

All experimental measurements were made in triplicate and values expressed as mean \pm standard deviation (SD). Statistical significance of differences in permeability enhancement and cell viability were examined using one-way analysis of variance (ANOVA) followed by LSD post-hoc test. Significance level was set at $p<$ 0.05 .

\section{RESULTS}

\section{Effect of chitosan salts on TEER}

The effect of different CS salt forms and concentrations on TEER of Caco-2 cell monolayers is summarized in Figs 1 - 4 . Incubation on the apical side of the monolayers with $0.001-1 \% \mathrm{w} / \mathrm{v}$ of the CS-salt solutions at $\mathrm{pH}$ of 6.2 for $2 \mathrm{~h}$ resulted in immediate reduction in TEER values compared with control group. The reduction was concentration-dependent with increase in salt concentration resulting in significant decrease $(p<0.05)$ in TEER 
compared with control. After removal of CS-salt solutions, recovery of the treated cells was monitored for TEER for $48 \mathrm{~h}$, and the results show increase in resistance CS-salt concentrations of $0.001-0.01 \% \mathrm{w} / \mathrm{v}$. with TEER recovery of $>60 \%$ of initial values within $24 \mathrm{~h}$ of CS-salt solution removal from the cells, indicating that the effect of CS-salt was reversible at lower concentrations. Drug transport studies were therefore investigated at a concentration of 0.01 $\% w / v$, being the safest and most effective enhancer concentration (Fig 1, 2).
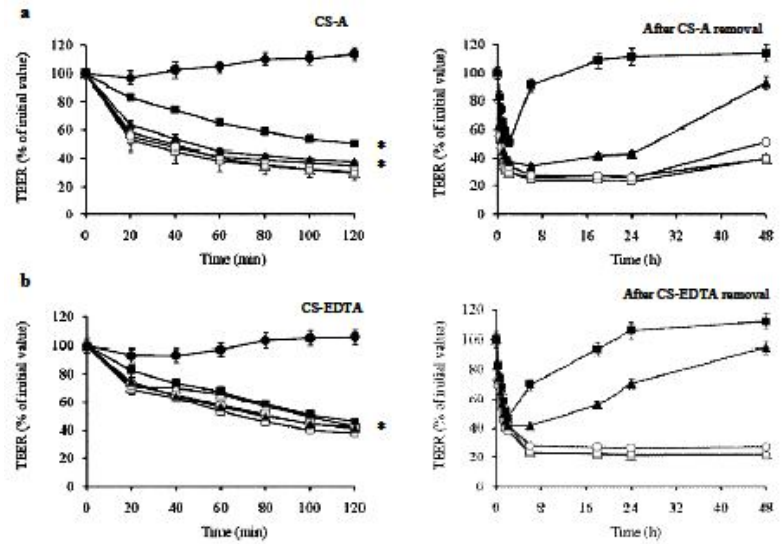

Figure 1: Effect of (a) CS-A, (b) CS-EDTA at concentrations ranging from $0.001-1 \% \mathrm{w} / \mathrm{v}$, at $\mathrm{pH} 6.2$ on TEER (left) and TEER recovery (right) of Caco-2

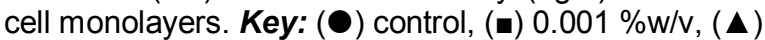
$0.01 \% w / v,(\bigcirc) 0.05 \% w / v,(\square) 0.1 \% w / v,(\triangle) 1 \% w / v$. Each point represents the mean of three experiments; ${ }^{*} p<0.05$
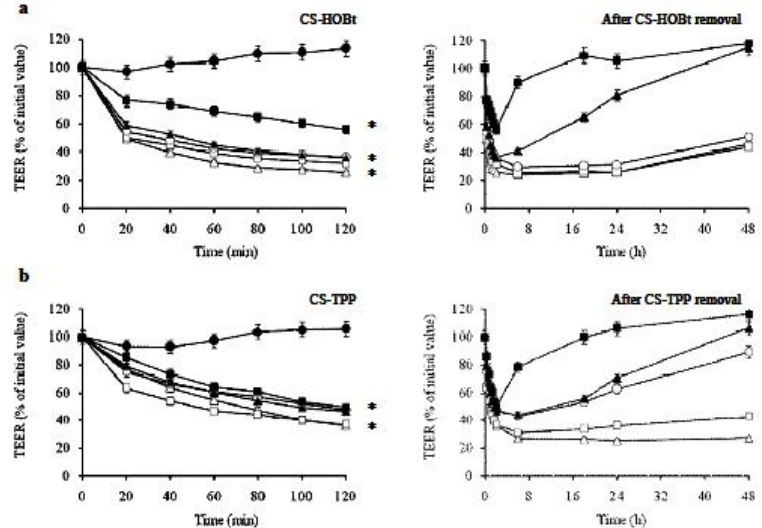

Figure 2: Effect of (a) CS-HOBt, (b) CS-TPP at concentrations ranging from $0.001-1 \% \mathrm{w} / \mathrm{v}$, at $\mathrm{pH} 6.2$ on TEER (left) and TEER recovery (right) of Caco-2 cell monolayers. Key: (O) control, ( $0.001 \% \mathrm{w} / \mathrm{v},(\boldsymbol{\Delta})$ $0.01 \% \mathrm{w} / \mathrm{v},(\bigcirc) 0.05 \% \mathrm{w} / \mathrm{v},(\square) 0.1 \% \mathrm{w} / \mathrm{v},(\triangle) 1 \% \mathrm{w} / \mathrm{v}$. Each point represents the mean of three experiments; ${ }^{*} p<0.05$

At $\mathrm{pH}$ of 7.4 , incubation on the apical side of the monolayer with the CS-salt solutions $(0.001-1$ $\% w / v)$ for $2 \mathrm{~h}$ resulted in no significant decrease $(p<0.05)$ in TEER for CS-A and CSTPP (Fig 3), but for CS-EDTA and CS-HOBt, there was concentration-dependent decrease ( $p$ $<0.05)$ in TEER at high concentrations $(0.5-1$
$\% w / v$ for CS-EDTA and $1 \% w / v$ for CS-HOBt). After removal of CS-salt solutions, increase in resistance towards initial values was found. However, cells treated with $1 \%$ w/v CS-EDTA solution showed only $50 \%$ recovery TEER in 48 $\mathrm{h}$, indicating that CS-EDTA had a very strong effect on the cells (Fig 4).

a
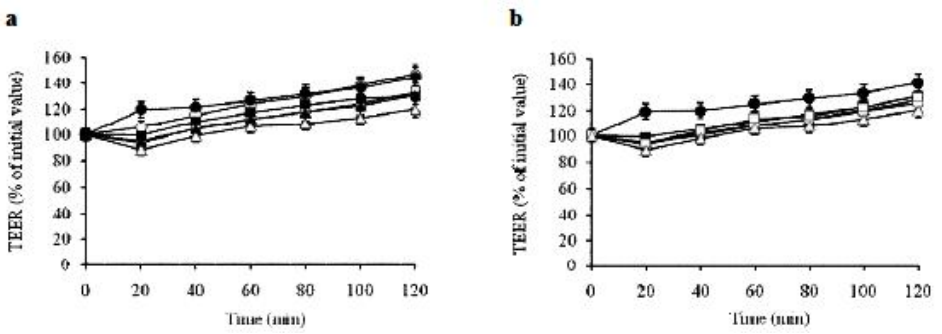

Figure 3: Effect of (a) CS-A and (b) CS-TPP at $\mathrm{pH} 7.4$ on TEER of Caco-2 cell monolayers. Key: (O) control, (घ) $0.001 \% w / v,(\Delta) 0.01 \% w / v,(\bigcirc) 0.05 \% w / v,(\square)$ $0.1 \% \mathrm{w} / \mathrm{v},(\triangle) 1 \% \mathrm{w} / \mathrm{v}$. Each point represents the mean of three experiments; ${ }^{*} p<0.05$
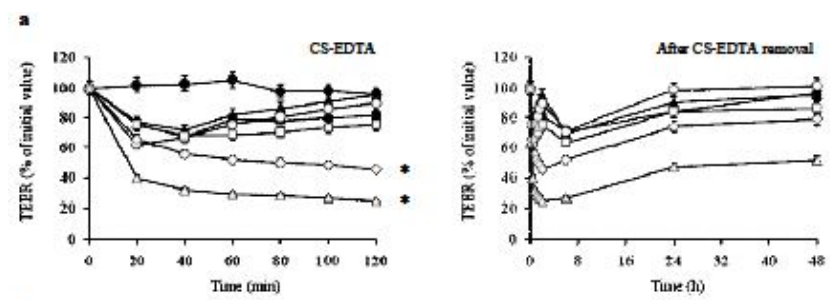

b
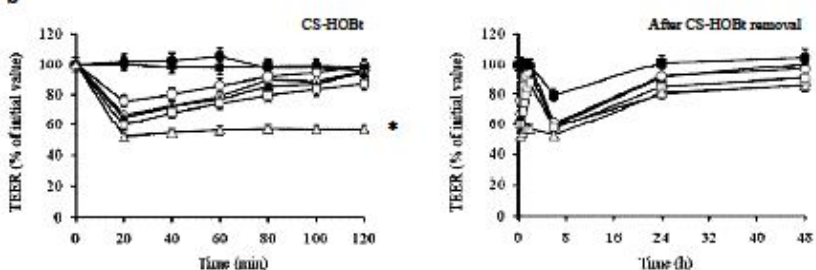

Figure 4: Effect of (a) CS-EDTA and (b) CS-HOBt at $\mathrm{pH} 7.4$ on TEER (left) and TEER recovery (right) of Caco-2 cell monolayers. Key: (O) control, (a) 0.001 $\% w / v,(\Delta) 0.01 \% w / v,(\bigcirc) 0.05 \% w / v,(\square) 0.1 \% w / v$, $(\diamond) 0.5 \% \mathrm{w} / \mathrm{v},(\triangle) 1 \% \mathrm{w} / \mathrm{v}$. Each point represents the mean of three experiments; ${ }^{*} p<0.05$

\section{Effect of chitosan salts on transport of FD-4}

Fig 5a shows the transport of FD-4 across the Caco-2 cell monolayers in the presence of CSsalt solutions at a concentration of $0.01 \% \mathrm{w} / \mathrm{v}$ at $\mathrm{pH} 6.2$ and in the absence of CS (control). Incubation with CS-salts resulted in accumulation of FD-4 in the acceptor compartment. All CS-salt solutions significantly increased $(p<0.05)$ transport of FD-4 unlike control which did not. These results correlate with TEER reduction data. On the other hand, at $\mathrm{pH} 7.4$ incubation, CS-EDTA produced the highest increase in transport of FD-4 while CS-HOBt did not significantly increase transport of FD-4, even at a concentration of $1 \% \mathrm{w} / \mathrm{v}$ (Fig $5 \mathrm{~b}$ ). Cumulative transport of FD-4, $P_{a p p}$, data and absorption 


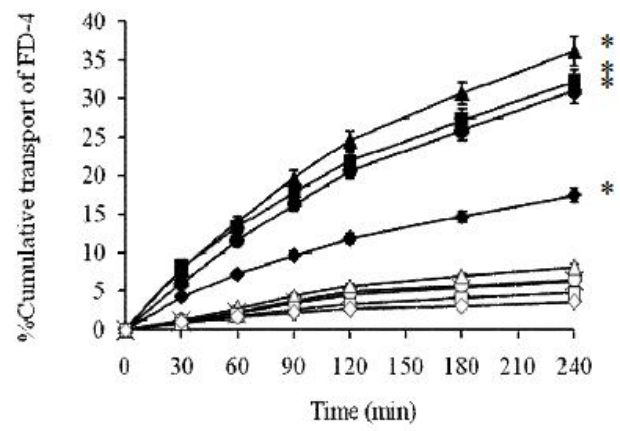

b

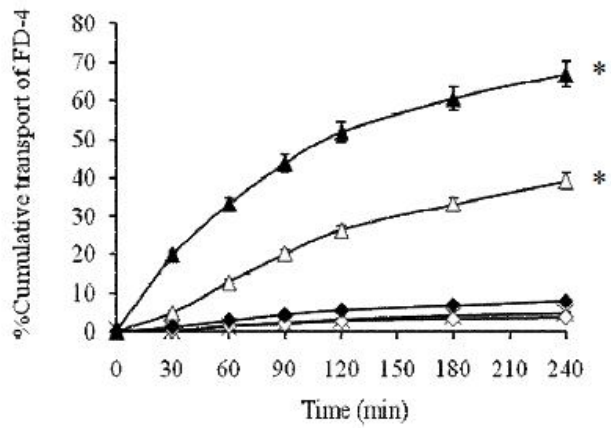

Figure 5: Cumulative transport of FD-4 in the presence of $0.01 \% \mathrm{w} / \mathrm{v}$ CS-salt solutions, at (a) pH 6.2: (O) CS-A, $(\boldsymbol{\Delta})$ CS-EDTA, $(\bullet)$ CS-HOBt, $(\bullet)$ CS-TPP, $(\bigcirc)$ A, $(\triangle)$ EDTA, $(\diamond) \mathrm{HOBt}$, ( $\square$ ) TPP and $(\times)$ control; and (b) pH 7.4: $(\Delta) 1 \% \mathrm{w} / \mathrm{v}$ CS-EDTA, $(\triangle) 0.5 \% \mathrm{w} / \mathrm{v}$ CS-EDTA, $(\bullet) 1 \% \mathrm{w} / \mathrm{v}$ CS-HOBt $(\diamond) 0.5 \% \mathrm{w} / \mathrm{v}$ CS-HOBt and $(\times)$ control. Each point represents the mean of three experiments; ${ }^{*} p<0.05$

Table 1: Effect of CS-salts on the transport of FD-4 (mean $\pm S D, n=3$ )

\begin{tabular}{lccccc}
\hline Sample & $\mathbf{p H}$ & $\begin{array}{c}\text { Conc. } \\
(\mathbf{\%} \mathbf{w} / \mathbf{v})\end{array}$ & $\begin{array}{c}\text { \%Cumulative transport } \\
\text { of FD-4 at } \mathbf{4} \mathbf{~ h}\end{array}$ & $\begin{array}{c}\boldsymbol{P}_{\mathbf{a a p}}{ }^{\mathbf{a}} \\
\left(\mathbf{1 0} \mathbf{0}^{-6} \mathbf{~ m} / \mathbf{s}\right)\end{array}$ & $\boldsymbol{R}^{\mathbf{b}}$ \\
\hline Control & 6.2 & - & $6.33 \pm 3.70$ & 0.40 & 1.00 \\
A & 6.2 & 0.01 & $6.56 \pm 0.10$ & 0.42 & 1.04 \\
EDTA & 6.2 & 0.01 & $8.14 \pm 6.10$ & 0.51 & 0.27 \\
HOBt & 6.2 & 0.01 & $3.55 \pm 0.60$ & 0.20 & 0.09 \\
TPP & 6.2 & 0.01 & $4.72 \pm 0.60$ & 0.29 & 0.28 \\
\hline CS-A & 6.2 & 0.01 & $30.95 \pm 4.90$ & 1.89 & 4.70 \\
CS-EDTA & 6.2 & 0.01 & $36.19 \pm 13.20$ & 2.19 & 5.45 \\
CS-HOBt & 6.2 & 0.01 & $17.47 \pm 3.60$ & 1.04 & 2.58 \\
CS-TPP & 6.2 & 0.01 & $32.22 \pm 7.50$ & 1.90 & 4.74 \\
\hline Control & 7.4 & - & $4.61 \pm 1.90$ & 0.31 & 1.00 \\
CS-EDTA & 7.4 & 0.5 & $39.29 \pm 1.80$ & 2.52 & 8.21 \\
CS-HOBt & 7.4 & 0.5 & $3.54 \pm 0.20$ & 0.23 & 0.75 \\
CS-EDTA & 7.4 & 1 & $67.01 \pm 4.10$ & 3.92 & 12.80 \\
CS-HOBt & 7.4 & 1 & $7.98 \pm 1.80$ & 0.50 & 1.65 \\
\hline
\end{tabular}

${ }^{\mathrm{a}} P_{\text {app }}=$ apparent permeability coefficient; ${ }^{\mathrm{b}} R=$ absorption enhancement ratio

Table 2: Cytotoxicity of CS salts incubated with Caco-2 cells for 2 and $24 \mathrm{~h}$ (mean $\pm S D, n=8$ )

\begin{tabular}{|c|c|c|c|}
\hline Sample & $\mathrm{pH}$ & $\frac{I C_{50}{ }^{a}(\% w / v)}{2 h}$ & $\begin{array}{r}\text { Sample } \\
24 \mathrm{~h}\end{array}$ \\
\hline CS-A & 6.2 & $>1$ & $0.10 \pm 0.03$ \\
\hline CS-EDTA & 6.2 & $0.25 \pm 0.06$ & $0.07 \pm 0.05$ \\
\hline CS-HOBt & 6.2 & $0.28 \pm 0.06$ & $0.15 \pm 0.11$ \\
\hline CS-TPP & 6.2 & $0.60 \pm 0.06$ & $0.15 \pm 0.04$ \\
\hline $\begin{array}{l}\text { CS-A } \\
\text { CS-EDTA } \\
\text { CS-HOBt } \\
\text { CS-TPP }\end{array}$ & $\begin{array}{l}7.4 \\
7.4 \\
7.4 \\
7.4\end{array}$ & $\begin{array}{c}>1 \\
0.30 \pm 0.05 \\
0.95 \pm 0.17 \\
>1\end{array}$ & $\begin{array}{c}>1 \\
0.20 \pm 0.03 \\
>1 \\
>1\end{array}$ \\
\hline
\end{tabular}

enhancement ratio $(R)$ are shown in Table 1

\section{Cytotoxicity}

The effect of CS-salts on mitochondrial dehydrogenase activity was expressed as $\mathrm{IC}_{50}$ with high value indicating low toxicity (Table 2). All the CS-salts tested showed concentration- dependent cytotoxicity in the Caco-2 cell model at $\mathrm{pH} 6.2$, but at $\mathrm{pH} 7.4$, only CS-EDTA showed concentration-dependent cytotoxicity. Cytotoxicity results varied among the salts used with CSEDTA the most toxic $\left(\mathrm{IC}_{50}\right.$ of $0.25 \pm 0.06$ and $0.30 \pm 0.05 \% \mathrm{w} / \mathrm{v}$ at $\mathrm{pH} 6.2$ and 7.4 , respectively, after $2 \mathrm{~h}$ incubation). 


\section{DISCUSSION}

$\mathrm{CS}$ is insoluble at neutral and alkaline $\mathrm{pH}$, but forms water soluble salts with inorganic and organic acids. CS-salts are soluble in water; their solubility being dependent on the degree of deacetylation and $\mathrm{pH}$ of the solution. Due to the positive charge of amine groups in CS structure it can be complexed with a negative charge of salt by electrostatic interaction. Many salts including aspartic acid, EDTA, HOBt and TPP present negative charge on their molecules, thus, improving CS water solubility and allowing CS to be dissolved in water.

TEER measurement can be used to evaluate possible damage of cellular monolayer during experiments and also tight-junction permeability. It measures the ionic permeability of the cell monolayer. Increase in the paracellular permeability of the cell monolayers shows as decrease in TEER. The results indicate that incubation with all four CS-salt solutions at $\mathrm{pH}$ of 6.2 decreased TEER but the treated cells fully recovered within $48 \mathrm{~h}$ after removal of low concentration (0.001 - $0.01 \%)$ CS-salt solution, indicating that these CS-salt are safe for use as absorption enhancers under the applied. These results could be confirmed with transport of FD-4 which showed that the transport of FD-4 across the Caco-2 cell monolayers in the presence of CS-salt solutions at the concentration of $0.01 \% \mathrm{w} / \mathrm{v}, \mathrm{pH} 6.2$, resulted in an accumulation of FD-4 in the acceptor compartment. A difference in the transport of FD-4 was found at different CS-salt forms as showed in Fig. $4 a$ and Table 1.

TEER and cytotoxic results could be explained by the fact that EDTA, a powerful metal chelating agent, might have disrupted cell-cell adhesion by depleting the extracellular $\mathrm{Ca}^{2+}$ required for the interaction of components of adherens junctions. Interactions between components of adherens junctions on adjacent epithelial cells maintains cell-cell adhesion and thus paracellular space. Therefore, chelation of $\mathrm{Ca}^{2+}$ may induce tight junction separation by physical disruption of cellcell adhesion [12]. The chelation of extracellular $\mathrm{Ca}^{2+}$ would also activate intracellular protein kinases that induce the disruption of junctional integrity. $\mathrm{Ca}^{2+}$ chelators function by activation of tyrosine kinases and the subsequent phosphotyrosine-regulated increase in paracellular permeability is effected by cadherin-catenin complex that comprises of the adherens junction [13]..

Therefore, chelation of $\mathrm{Ca}^{2+}$ would not just physically abolish cell-cell adhesion; instead, it would specifically activate a signal transduction cascade that regulates junctional integrity

In addition, EDTA is soluble at alkaline $\mathrm{pH}$. This might be the reason for CS-EDTA to have exerted its effect on the cells even at pH 7.4. EDTA is one of the best chelation products for removal of unwanted metals (in particular, calcium, mercury, lead, cadmium, and arsenic) from the body's organs and cardiovascular system [14]. It is approved by United States Food and Drug Administration (FDA) for this use. However, it should be noted that there are various types of EDTA. Some are used for industrial purposes while others are of food and/or pharmaceutical grade for human consumption. It is also important to consider the method of administering EDTA. It is taken orally (liquid, capsule, sublingually), by suppository, and through IV. There are varying degrees of safety and effectiveness for each route of administration.

For most paracellular permeation enhancers, there is little difference between their cytotoxicity and ability to increase paracellular efficacy. Thus, the ability of many enhancers to increase paracellular permeability is not a direct result of their toxic actions [15].

The cytotoxicity of enhancers is determined by several methods. In the present study, two methods were employed; MTT assay and TEER measurement. MTT is actively absorbed in a succinate $\mathrm{NADH}^{+}$mitochondrial-dependent reaction to yield a formazan product. The ability of the cells to reduce MTT provides an indication of mitochondrial activity that is interpreted as a metabolic marker for cell viability. This process requires active mitochondria, and even freshly dead cells do not cleave significant amounts of MTT. A drawback of the assay is that it does not distinguish between a cytotoxic (cell kill) and a cytostatic (reduced growth rate) effect[11,16]. Moreover, MTT assay measures the effect of a drug on the growth of a population of cells whereas TEER measurement measures the effect of a drug on differentiated cells. For these reasons, MTT assay seems to be a more sensitive indicator of chemical exposure than TEER measurement. In fact, MTT model reveals that at equivalent $\mathrm{IC}_{50}$, mitochondrial activity is more likely to be altered before paracellular permeability is compromised. Very often researchers use only TEER to estimate the possible cytotoxic effects of compound under investigation. However, the relationship between TEER and cytotoxicity is not very clear and is non-linear; above a certain level of TEER, very small increases in junctional permeability may 
produce large decreases in resistance, while at low-resistance values relatively large changes in transjunctional flux of tracer will often be associated with very modest changes in TEER [17]. Additionally, decrease in TEER is not necessarily predictive of a cytotoxic effect as this decrease is reversible. Therefore, the best way to assess cytotoxicity is to combine different techniques.

\section{CONCLUSION}

Among the CS salts evaluated, CS-EDTA is the best of absorption enhancer but was also the most toxic. In general, CS salts enhanced drug absorption across Caco-2 cell monolayers, with CS-EDTA in particular demonstrating a potential as a good absorption enhancer.

\section{ACKNOWLEDGEMENT}

The authors wish to thank Silpakorn University Research and Development Institute for financial support.

\section{REFERENCES}

1. McCurdy JD. FDA and the use of chitin and chitosan derivatives. Advances in Chitin and Chitosan. London and New York: Elsevier Applied Science, 1992; $p p$ 659-662.

2. Kotze AF, Lueßen HL, Boer BGD, Verhoef JC, Junginger HE. Chitosan for enhanced intestinal permeability: prospects for derivatives soluble in neutral and basic environments. Eur J Pharm Sci 1999; 7: 145-151.

3. Cerchiara T, Luppi B, Bigucci F, Zecchi VChitosan salts as nasal sustained delivery systems for peptidic drugs. J Pharm Pharmacol. 2003; 55: 1623-1627.

4. Chae Y, Jang MK, Nah JW. Influence of molecular weight on oral absorption of water soluble chitosans. J Control Rel 2005; 102: 383-394.

5. Weecharangsan $W$, Opanasopit $P$, Ngawhirunpat $T$, Apirakaramwong A, Rojanarata T, Ruktanonchai U, Lee RJ. Evaluation of chitosan salts as non-viral gene vectors in CHO-K1 cells. Int J Pharm 2008; 348: $161-168$.
6. Rojanarata $T$, Opanasopit $P$, Techaarpornkul $S$, Ngawhirunpat $T$, Ruktanonchai U. ChitosanThiamine Pyrophosphate as a novel carrier for siRNA delivery. Pharm Res 2008; 25: 2807-2814.

7. Engel P.C. Enzyme cofactors. In P.C. Engel (Ed), Enzymology LabFax, Academic Press, California, 1996; pp 244-245.

8. Opanasopit $P$, Aumklad $P$, Kowapradit J, Ngawhirunpat $T$, Apirakaramwong A, Rojanarata $T$, Puttipipatkhachorn S. Effect of salt forms and molecular weight of chitosans on in vitro permeability enhancement in intestinal epithelial cells (Caco-2). Pharm Dev Technol 2007; 12(5): 447-455.

9. Charernsriwilaiwat $N$, Opanasopit $P$, Rojanarata $T$, Ngawhirunpat $T$. In vitro antioxidant activity of chitosan aqueous solution: Effect of salt form. Trop J Pharm Res 2012; 11(2): 235-242.

10. Kotze AF, Lueßen HL, Leeuw BJD, Boer BGD, Verhoef $J C$, Junginger HE. Comparison of the effect of different chitosan salts and $\mathrm{N}$-trimethyl chitosan chloride on the permeability of intestinal epithelial cells (Caco-2). J Control Rel 1998; 51: 35-46.

11. Berridge MV, Herst PM, Tan AS. Tetrazolium dyes as tools in cell biology: new insights into their cellular reduction. Biotechnol Annual Rev 2005; 11: 127152.

12. Quan YS, Hattori K, Lundborg E, Fujita T, Murakami M, Muranishi S, Yamamoto A. Effectiveness and toxicity screening of various absorption enhancers using Caco-2 cell monolayers. Biol Pharm Bull 1998; 21: 615-620.

13. Behrens J, Vakaet L, Friis R. Loss of epithelial differentiation and gain of invasiveness correlates with tyrosine phosphorylation of the E-cadherin/ $\beta$ catenin complex in cells transformed with a temperaturesensitive v-SRC gene. J Cell Biol 1993; 120: 757-766.

14. El-Sharif AA, and Hussain MHM. Chitosan-EDTA new combination is a promising candidate for treatment of bacterial and fungal infections. Curr Microbiol 2011; 62: 739-745.

15. Ward PD, Tippin TK, Thakker DR. Enhancing paracellular permeability by modulating epithelial tight junctions. Pharm Sci Technol Today 2000; 3 : 346-358.

16. Smith MD, Barbenel JC, Courtney JM, Grant MH. Novel quantitative methods for the determination of biomaterial cytotoxicity. Int J Artif Organs 1992; 15: 191-184.

17. Sambruy Y, Ferruzza S, Ranaldi G, De Angelis $I$. Intestinal cell culture models: applications in toxicology and pharmacology. Cell Biol Toxicol 2001; 17: 301-317. 